Transactions of the American Philological Association 131 (2001) 289-296

\title{
What Good Is a Rebellious Teenager? Classics and Linguistics in the Twentieth Century
}

\author{
Eleanor Dickey \\ Columbia University
}

In looking at traditional specialties within the APA, one cannot get any more traditional than linguistics. ${ }^{1}$ This is because, in the beginning, the American Philological Association was not an organization of classicists at all; it was an organization of scholars interested in language, any language. The justification for the founding of the association, as printed in the first issue of TAPA, was to provide a society for "the professors, friends, and patrons of linguistic science in America." The contents of the first volume of TAPA show what this meant: there were papers entitled "On the nature and theory of the Greek accent," "On the nature and designation of the accent in Sanskrit," "On the aorist subjunctive and future indicative with ö $\pi \omega s$ and ou $\mu$ ń," "On the best method of studying the North American languages," "On the German vernacular of Pennsylvania," "On the present condition of the question as to the origin of language," "On certain forms of the English verb which were used in the sixteenth and seventeenth centuries," "On some mistaken notions of Algonkin grammar, and on mistranslations of words from Eliot's Bible," and "Contributions to Creole Grammar." In other words, out of nine papers, two were on Greek, one was on Sanskrit, one was on the origin of language, and the remaining five were on various modern languages. None was on history, literature, or any other non-linguistic topic.

The fact that the American Philological Association was not originally an organization of classicists at all sheds some light on its name. If you look up the word "philology" in most American dictionaries, you will find a variety of different meanings, but none of them is "classics." Philology can mean linguistics, or it can mean the study of languages, literatures, and cultures in a general sense,

${ }^{1}$ I am grateful to Roger Bagnall, Adam Blistein, and especially Philomen Probert for their help and advice with this paper. 
and it can often mean other things as well, but it normally does not mean "classics." People who know this sometimes wonder why the main American classics organization is called the American Philological Association, when in England, for example, the main organization of classicists is called the Classical Association, and the Philological Society, which also exists, is an organization of linguists, most of whom work on modern languages. But in order to solve that problem properly, you have to turn the question around and ask not why the main American classics organization is called the American Philological Association, but why the American Philological Association is an organization of classicists.

Back in 1869, when the APA was founded, American higher education was only beginning the process of professionalization that would eventually lead to the university system we know today. The humanities had not yet been broken down into subjects and departments, and "philology" in the broad sense of languages, literatures, and cultures was used in situations not radically different from those where we might now use "humanities." So the founders of the APA were establishing a professional organization for philology in the broad sense, that is for scholars interested in languages, literatures, and cultures, and it was simply understood that naturally language was the most prominent of these angles and culture the least prominent. But the founders were well aware that the new society covered a huge area, and so at the first meeting they drew up a list of seven subfields into which papers could be divided for separate sessions once the organization got big enough to hold more than one session at annual meetings. ${ }^{1}$ These seven subfields were:

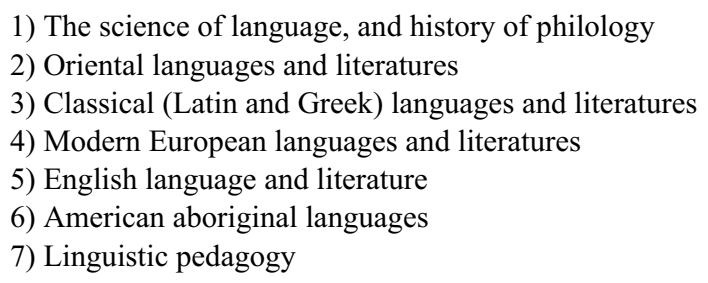

Now these seven subfields did not all have equal status. The third, Latin and Greek languages and literatures, was acknowledged to be the largest and most important. It was also the oldest, since the systematic study of other languages and literatures, and the discipline of linguistics itself, had grown out of the study of Latin and Greek in the preceding century. Nevertheless all seven fields, and a number of others as well, are in fact represented in early issues of TAPA.

\footnotetext{
${ }^{1}$ See proceedings of first meeting, TAPA 1 (1869-70) 6.
} 
As the founders had anticipated, the different fields grew rapidly, and soon the minority subjects became large enough to have sessions of their own. It turned out, however, that what their practitioners wanted was not separate sessions at APA meetings, but rather their own professional organizations. The archaeologists are the ones who started the trend, splitting off to form the Archaeological Institute of America in 1879, only ten years after the founding of the APA. They were soon followed by the Society of Biblical Literature, founded in 1880, the Modern Language Association, founded in 1883, and the American Historical Association, founded in 1884. The classicists, who were always the largest group within the APA and became a larger percentage of the membership every time another group split off, never felt the need for a society of their own, and as a result by 1900 we had the APA largely to ourselves.

The practitioners of linguistic science, however, did not form their own society until 1924, and until that time they were distributed among a number of different professional societies, with about a third of them in the APA. As a result the APA in 1900 was involved in a number of activities which today we would consider linguistics rather than classics, such as leading a campaign to reform English spelling. The APA supported a drastically revised spelling system not only by lobbying efforts, but also by using the reformed spellings in $T A P A$ on occasion, which makes certain portions of the early proceedings remarkably difficult to read.

The APA only became strictly an organization of classicists, that is of people interested in the ancient world, when the Linguistic Society of America was founded in 1924. On this occasion the president of the APA sent a letter to the new society in which he compared its members to Greek colonists and the APA to the metropolis, expressing hopes that ties of "filial affection" would continue to bind the two organizations.

At first the colonists did maintain a close relationship with the mother organization, often sharing joint annual meetings, but as is so often the case, filial affection started to disappear when the younger group grew old enough to rebel. Many linguists developed an attitude of scorn for dead languages with their limited possibilities for data collection, and they discovered that they could make their lives much easier by dispensing with certain ideas long cherished by classicists, such as the notion that good literature is more worth working on than bad literature or colloquial language.

So linguistics is the rebellious teenager in my title, and classics is its longsuffering parent. And as is often the case, the teenager made some impressive accomplishments with the energy and determination of youth. Working on modern languages, with unlimited quantities of fresh evidence at their disposal, the 
linguists were able to come up with ideas which, however much it may pain the parent to admit it, would never have been discovered by people working only or even primarily on Latin and Greek. The whole science of phonetics, for example, could not possibly have evolved without studying live native speakers of a range of languages. And sociolinguistics, the study of the way that different groups in society use language differently, would not have developed out of the Latin and Greek literature we possess, where linguistic variations due to age, class, and gender are so often hidden by a desire for uniform literary elegance.

What has been the reaction of classics to all this? On the whole, the parent has been tolerant of the breaches of filial affection and tried to maintain a good relationship despite the waywardness of the younger member of the family. And the rewards of a relationship with linguistics have been considerable. The fact that the discoveries of linguists working on modern languages could not have been made on the basis of a study of Latin and Greek does not mean that they are not applicable to Latin and Greek-far from it. Sociolinguistics, for example, can help identify and explain traces of women's language, military language, and the language of other groups within the Greco-Roman world. This in turn can alert us to what the texts we have are telling us about those groups, and aid in the recovery of their places in the classical world.

In fact, as a result of the discoveries of modern linguistics, the focus of linguistics as applied to Latin and Greek has changed dramatically in the course of the past century. I began by saying that there is no specialty within the APA more traditional than the linguistic one, and in one way that is true. Yet in another way the linguistic work now being done on Latin and Greek is some of the least traditional work in classics, because the focus of its interests has changed so radically. Rarely now does one find a paper on the topics which dominated linguistic classics a century ago. Then, most scholars focused on stylistic issues, on the use of various constructions, and on observations that would lead their readers to the ability to write more perfect classical Latin and Greek. Now, on the other hand, we are much more likely to look at topics like women's language in Greek and Latin, ancient bilingualism and its social implications, or what the Greek dialects meant to their speakers. The reasons for this shift are clear: modern linguistics has given classicists tools that enable them to tackle interesting subjects which were previously very difficult to study, and which indeed it might never have occurred to anyone to study if these topics had not been successfully explored in modern languages.

Let me give you some more specific examples of how this works. Latin and Greek texts are full of vocatives, and some of those vocatives are pretty strange. Greeks tend to use terms of affection such as $\phi[\lambda \varepsilon$ "dear" to distant acquain- 
tances at moments when they clearly are not feeling very affectionate, while Romans seem to have used domine "master" both to their own fathers and to distant acquaintances whose names they had forgotten. Many attempts have been made to explain these terms, both in terms of working out what they actually meant to the people who used them and in terms of understanding why they meant what they meant, but until recently there had been very little success.

Modern languages, however, have addresses that are just as strange, though in different ways. Why is there such a difference between addressing an American as "Bill" or as "Mr. Clinton"? Why do Germans who use $d u$ for "you" when they should use the more formal Sie sometimes end up in court being ordered to pay substantial fines to the people they have so insulted? Linguists working on these and other problems of addresses in modern languages have formulated two key rules that are crucial for understanding addresses in any language. The first of these is that words do not necessarily mean the same thing, and are not necessarily used the same way, in address, that is when talking to the person they refer to, as in reference, that is when talking about the person they refer to. The second is that choice of addresses depends just as much on the status and identity of the speaker as on the status and identity of the addressee.

One might be inclined to doubt whether these rules actually work, but in fact they do, and both of them can be illustrated from English. For example, I could have begun this talk by saying "Good evening, Ladies and Gentlemen," but without sounding extremely peculiar I could not have begun it by saying, "Good evening, APA." On the other hand, when talking about this audience rather than addressing it directly, I could and did say "I'm scared to death about that talk I'm giving to the APA," but my colleagues would have thought something was seriously wrong with me if I had said "I'm worried about the paper I'm giving to the Ladies and Gentlemen." Similarly, the word "madam" can be used in English to mean "a woman who runs a brothel," for example in contexts like "Seventy-five madams were rounded up in a single night." But when one uses "madam" in address, for example in sentences like "Would you care for some wine, madam?," it is a perfectly polite term and certainly does not imply that the addressee derives any part of her income from prostitution.

As for the difference that the speaker makes, consider the different ways that one individual may be addressed by different people in English. For example, if I met Hillary Clinton, I would call her "Mrs. Clinton," but I doubt that Chelsea Clinton calls her that, and I would be surprised if Bill Clinton called her "Mom."

Both of these look like pretty simple observations when put this way, but it is a historical fact that until modern linguists pointed them out and proved their 
validity by systematic studies, no-one had used them. Scholars started from the assumptions that a word ought to mean the same thing in the vocative as it does in any other case, and that in examining address usage they did not have to pay attention to the identities of speakers.

But now, applying these two rules to Latin and Greek, we can see that their address systems are even more peculiar than they looked before. Greeks called each other $\phi[\lambda \varepsilon$ to indicate a sense of superiority, and Romans used domine so widely not because they liked to talk like slaves - in fact slaves did not use this address to their masters - but because the address indicated the same kind of generalized affection and respect as pater "father," which the Romans also used in the same way. There are also many other examples of insights that can now be gained into vocative usage, such as the observation that the Greeks were happy to include women and children along with men in the referential usage of the word "̋ $v \theta \rho \omega \pi$ os "human being," but they restricted the vocative ö $v \theta \rho \omega \pi \varepsilon$ to adult men-in fact normally to adult male citizens. Now this last point, of course, has something to do with the way the Greeks divided up the world, into the adult male citizens and everyone else, and so, like the other points I've mentioned, it ties in with a lot of other recent work on the Greeks which started from a completely non-linguistic perspective.

There are many other areas of linguistic classics which show a similar shift in focus over the past century, but one major area seems to be a counterexample to this process. Indo-European historical linguistics is still working on the same sort of questions as those it was attempting to answer a century ago. Scholars are still engaged in reconstructing features of the parent language from which Latin, Greek, Sanskrit, and the other Indo-European languages are descended. Perhaps one reason this field has remained so consistent in its goals is that it is one in which remarkable progress has been possible without changing the goals. The twentieth century has seen some of the most important breakthroughs in this area. One thinks first of the decipherment of Linear B and the discovery of what Mycenaean Greek was like, but in the past century Hittite, Luvian, and Tocharian, to name only the most important, have also been added to our inventory of ancient Indo-European languages. These discoveries had in many ways more to do with archaeology than with linguistics, but linguistics has been crucial to our ability to understand these new languages, as well as for our understanding of language evolution in general.

So in fact classics has drawn considerable advantage from the work of its rebellious offspring over the course of the past century. What will the next century bring? In the short run, the trend we have been seeing is almost certain to continue, since the application of some linguistic work to the ancient world is 
only beginning. Study of bilingualism in antiquity, for example, is likely to yield exciting information not only about language use but also about the way that members of different cultures perceived each other. If it turns out to be true that a highly Latinized form of Greek was the language of love in Rome, for example, what does that mean?

Another likely development in the next century will be increased study of postclassical, subliterary, and other nonstandard varieties of Greek and Latin. Such study has already begun and produced good results, and it is partly the result of classics taking over from linguistics the idea that non-literary language is just as worthy of study as any other form of language. I suspect that in the next century people working on modern linguistics will take over from classics the corollary of this idea, namely that the language of good literature is just as worthy of study as any other kind of language. This corollary is only one of a number of benefits that closer cooperation with classics has to offer linguistics, and indeed such closer cooperation is almost certain to occur. It will be fostered not only by its inherent advantages for both disciplines, but also by the increased popularity of interdisciplinary work in American academia. The fact that linguistics is no longer a teenager and does not have to worry about establishing itself as a separate discipline, and the growing popularity of classics at many institutions, will also contribute to a closer relationship between the disciplines. The resulting cooperation will, I believe, be greatly beneficial to both sides and result in work that is more fruitful for both classics and linguistics. 


\section{Bibliography}

Adams, J. N. (forthcoming). Bilingualism and the Latin Language.

Colvin, S. 1999. Dialect in Aristophanes. Oxford.

Dickey, E. 1996. Greek Forms of Address: From Herodotus to Lucian. Oxford.

Dickey, E. (forthcoming 2002). Latin Forms of Address: From Plautus to Apuleius. Oxford.

Hall, J. M. 1997. Ethnic Identity in Greek Antiquity. Cambridge. 143-81.

Mickey, K. 1981. "Dialect Consciousness and Literary Language: An Example from Ancient Greek." Transactions of the Philological Society 1981: 35-66.

Morpurgo Davies, A. 1987. "The Greek Notion of Dialect." Verbum: Revue de linguistique publiée par l'Université de Nancy II 10: 8-28.

Shero, L. R. 1963. "The American Philological Association: An Historical Sketch." TAPA 94: $\mathrm{x}-1$.

Proceedings of organizational meetings of the APA are in TAPA 1 (1869-70), of the LSA in Language 1 (1925). 